\title{
TRABALHO E EDUCAÇÃO EM TEMPOS DE PANDEMIA: ENTREVISTA COM MARCOS SUPERVIELLE'
}

\author{
Por Ana Paula F. D’Avila e Eduardo V. Bonaldi²
}

\section{Resumo}

Nesta entrevista, Marcos Supervielle, professor emérito da Udelar (Uruguai), aponta para uma série de questões suscitadas pela pandemia no Uruguai e, de modo geral, na França. Entre os temas abordados estão o isolamento dos trabalhadores, principalmente dos docentes, devido ao trabalho remoto, a imbricação do trabalho no cotidiano das famílias, a "boa onda" descrita pelo entrevistado como uma forma de aceitação tácita de más condições de trabalho, devido ao Covid-19. Por fim, explora-se o tema do Estado ao lidar com a pandemia e o papel dos sindicatos.

Ana Paula e Eduardo: Estimado profesor Marcos Supervielle, agradecemos su aceptación para participar en la entrevista. El objetivo de este dossier es reflexionar sobre el trabajo y la educación en el contexto de la pandemia provocada por el SARS-CoV-2, conocido popularmente como Covid-19. En este sentido, la primera pregunta es sobre la difusión del teletrabajo, durante la pandemia. ¿Cómo ha afectado esto a los límites entre el ámbito privado-familiar y el ámbito laboral?

Marcos: Yo lo que diría es que es muy importante ver esta relación del teletrabajo y la esfera familiar en el contexto del Covid-19, porque se me ocurre que hay muchos trabajadores que trabajan en sus casas, y eso de alguna forma, implica ajustes del tipo familiar. Con el Covid-19 esta

\footnotetext{
1 Ver currículo do entrevistado no final do texto. Essa entrevista on-line foi realizada no dia 11 de novembro de 2020 através da plataforma WEBConf da Universidade Federal de Pelotas (UFPel).

Transcrição realizada por Ana Paula F. D’Avila, revisada por Henrique Jeske, graduando em Ciências Sociais (UFPel), Agustina Martiarena, mestranda do Programa de Pós-graduação em Ciência Política da UFPel e Pedro Robertt (Editor da Norus.). Contou com a revisão final do autor.

Tratou-se de uma entrevista no calor do momento histórico que se está vivenciando, de crise sanitária global e de mudanças intensas no mundo do trabalho, sem preparação prévia. O autor deixou registrado que os argumentos apresentados estão baseados em tendências sociais contemporâneas e em hipóteses que precisam ser melhor desenvolvidas.

2 Ana Paula Ferreira D'Avila é pós-doutoranda em Sociologia pela Universidade Federal de Pelotas (UFPel). Doutora em Sociologia pela Universidade Federal do Paraná (UFPR), com estágio doutoral no Centro de Estudos Sociais da Universidade de Coimbra (UC), Portugal. E-mail: anapaulasocio10@gmail.com Cidade: Pelotas.

Eduardo Vilar Bonaldi é Professor Adjunto do Departamento de Sociologia e Ciência Política da Universidade Federal de Santa Catarina (UFSC). Professor do Programa de Pós-Graduação em Sociologia e Politica (UFSC). E-mail: eduvilarbon@gmail.com Cidade: Florianópolis.
} 
situación se expandió enormemente y generó una serie de problemas que me parece importante tener cuenta. Por lo menos acá en Uruguay, generó muchos problemas. En efecto, en Uruguay, el teletrabajo se dio fundamentalmente en la educación, y ello mucho más que en la producción. Es cierto que, en algunos sectores, por ejemplo, en el sector financiero, de alguna forma el teletrabajo tuvo su impacto, pero donde más lo tuvo fue en el sector educativo. Y esto generó una situación muy particular, porque pasaba que muchos docentes jóvenes tanto en el sector primario, en primeros años de educación; como en secundaria; como en la universidad, los docentes están casados con otros docentes. Entonces hubo una especie de eclosión de compartir tiempos entre los dos docentes que tenían que compatibilizar horarios, equipamientos, tareas del hogar de una forma muy poco planificada pero urgente. A ello hay que sumarle que, muchas veces eran padres y los chicos también estaban en una relación de teleducación, no de teletrabajo, pero sí de teleeducación, y muchas veces estos niños necesitaban el apoyo de sus padres, que ya estaban sobrecargados. Se dio una conjunción terrible de tensión por esta especie de continuo trabajo, vinculación entre sí, exigencia de espacios físicos de silencio, y chicos que no entendian porque los padres estando en la casa, no se podian ocupar de ellos. Fue una relación muy, muy especial y que creo que, de alguna forma, desgraciadamente, no se ha procesado y sistematizado por si vuelve a suceder.

Otro de los problemas que se planteó y que me parece que es muy importante a tener en cuenta es que, en términos generales en el sistema educativo en Uruguay - y yo acabo de terminar una investigación al respecto -, de alguna forma los docentes tienen una orientación muy de tipo expresiva - y no instrumental - con respecto al trabajo. Se sienten de alguna forma realizados a través de la docencia y, por tanto, no solamente sienten que están haciendo un trabajo para ganarse su vida, sino que de alguna forma tratan de proyectarse a través de la propia docencia. Les importa mucho, por lo tanto, el aspecto del resultado educativo de su trabajo, es decir, cómo los chicos se educan. En ello se encontraron con una serie de problemas. Por qué se dieron cuenta, que el resultado educativo por teletrabajo no es igual, no tiene la misma receptividad en los estudiantes que son de clase media y 
de clases altas - que de alguna forma tienen una cierta práctica de computación - y los chicos de clases bajas; y como consecuencia, el aprovechamiento de los chicos era relativamente más bajo en las clases populares que el promedio general. Esta situación generó una serie de tensiones. Pero, además, sentían que no estaban preparados para dar clases por teletrabajo, ya que fue todo muy espontáneo, muchas veces no tenía los equipos [de informática] acordes a las necesidades de dictar y animar clases por teletrabajo.

En realidad, me estoy yendo un poco del tema de la relación familia y teletrabajo, pero quiero decirles que todo esto hace al contexto en el cual esto generó algunas tensiones que fueron muy importantes en el seno de la familia. Mencionaba la relación de los chicos con los padres. Desgraciadamente en Uruguay no tenemos buenas estadísticas acerca de las tensiones intrafamiliares. Yo estuve rastreando los bancos de datos, y por ejemplo los franceses. En ellos se señalan que hoy en Francia el 10\% de las familias tienen mala relación al interior de la familia, están en situación de pre-divorcio, hay una situación de violencia, etc. Repito, representan el 10\% de la población las familias francesas. Pero la situación de estar comprimidos en la casa no aumentó este 10\%; quizás al interior de este grupo, sí agravó la situación de violencia, pero no aumentó la cantidad de las familias que tenían en situaciones de violencia. La otra punta, está menos estudiada, las familias que andan muy bien y que seguramente se beneficiaron de esta situación, de digamos estar oprimidos en un espacio, el espacio familiar. Hay pocas estadísticas al respecto, pero daría la impresión de que esas familias se fortalecieron todavía más en sus lazos internos. Entonces tenemos estos dos polos, que de alguna forma no se modificaron en términos relativos. Lo que es muy probable es que se hallen modificadas las relaciones al interior de la familia de cada uno de los grupos. Esto es más o menos lo que yo quería decir, lo que es más interesante que quería decir.

Eduardo: Solamente para poder aclarar un poco. Tú nos dijiste entonces que no ha aumentado la violencia intrafamiliar en Francia durante el periodo ¿Ha aumentado o no ha aumentado? 
Marcos: ¡No! No ha aumentado la cantidad en porcentaje de familias, en la totalidad de las familias con situaciones, no ha aumentado la cantidad. Capaz que hay familias que tenian situaciones de violencia y ahora no las tienen, capaz que hay familias que no las tenían y que ahora la tienen, pero el porcentaje de $10 \%$ de situaciones de familias con eventos de violencia se mantiene en Francia. Lo que sí digo, es que seguramente cambió el nivel de violencia al interior de estas familias que ya tenian.

Eduardo: ¿Qué categoría estás utilizando? ¿Familias que pasan por crisis familiares?

Marcos: En que hay señales de crisis familiares, exactamente. Yo soy un sociólogo del trabajo y más me oriento al ejercicio del trabajo, esto de la relación con la familia y el problema del teletrabajo en relaciones de familia es marginal en lo que yo estaba tratando de averiguar. Puedo pasar a otro al otro tema que es el tema del teletrabajo y la sociabilidad.

Ana Paula e Eduardo: ¿Cómo ha impactado el teletrabajo en las dinámicas de sociabilidad, jerarquía y disciplina en el ámbito laboral?

Marcos: Yo, sobre este tema, primero quiero decir que - y acá sí lo pongo en el marco de esfera problemática del trabajo en concreto - hay varias preocupaciones al respecto, y varias conductas que uno percibe, que se están dando a partir de ciertas preocupaciones manifestadas que hay sobre el problema de la sociabilidad. En primera instancia, un problema que surge por todos lados es el problema de la pérdida de la competencia colectiva. Es decir, al estar aislado de los equipos de trabajo, de los ámbitos colectivos de trabajo, etc. hay una pérdida muy grande, que es la pérdida de las competencias colectivas. Particularmente, de lo que se llama técnicamente las competencias no cognitivas, es decir, aquellas competencias que fueron adquiridas por fuera del sistema educativo pero que, de alguna forma, son fundamentales para el trabajo. Por ejemplo, dentro de las competencias no cognitivas está toda la dimensión afectiva, es decir, sentirse parte de un grupo, sentirse acompañado en caso de incidentes no previstos. Piensen 
ustedes, seguramente ustedes han pasado por eso - casi me pasa a mí - no podía conectarme. Sabía que llegaba la hora [de un compromiso laboral] y no tenía alguien que me ayudase, a ver que debía hacer, qué protocolo me había olvidado para poder comunicarse, etc. Todo esto genera una sensación de impotencia que no sucede si uno puede preguntarle informalmente al compañero de trabajo si está a su lado. Entonces, la cuestión que hace al sistema - y que es absolutamente central en los funcionamientos de los colectivos de trabajo -, no pasa por lo cognitivo sino pasa por lo no cognitivo; y desgraciadamente siento que esta dimensión se ha trabajado poco en la academia, aunque es fundamental y ello se constata en el teletrabajo. Por ejemplo: ustedes son docentes y seguramente tienen la experiencia de cómo enfrentar una clase y nadie les ha enseñado cuando hay que hacer un chiste, o cuando hay que referirse a un alumno en concreto, eso no aparece en los libros. Sin embargo, hace 50 años que soy docente universitario, y obviamente lo he aprendido. En este tipo de cuestiones uno siente una enorme carencia, cuando se hace el teletrabajo, porque uno se siente muy aislado. Y lo está en los dos planos, por un lado, en el de la relación con el colectivo; y, por el otro, en que muchas veces no tengo a quien recurrir en situaciones de incidentes, cosas que no estaban previstas o que yo por lo menos no tenía previsto, y que no las sé resolver. Esto genera una enorme inseguridad y cuanto más viejo uno está, más se siente más inseguro se queda ante este tipo de cosas.

Con respecto a la sociabilidad, este es un tema muy importante. En este momento hay todo un movimiento en Europa que está trabajando mucho con encuestas a los managers, a las asociaciones de managers y, particularmente, las que tienen una gran participación los managers de las grandes multinacionales. Todos plantean que están frente a un problema grave, que la presión para ir al teletrabajo de alguna forma los deja con enorme inseguridad de cómo van a funcionar los colectivos de trabajo, cómo va a funcionar la coordinación, como va a funcionar el involucramiento en el trabajo con esta modalidad. Entonces, esto es un tema bien importante y que de alguna forma ha generado resistencias. No solamente por parte de los trabajadores, sino también de los managers, a volcarse totalmente a este sistema de trabajo. Por ejemplo, ya hemos a veces mencionado Francia. E1 
Gobierno francés, en este momento - en su lucha contra el coronavirus y contra la segunda ola del coronavirus - está tratando de imponer al máximo el teletrabajo; y, curiosamente, son las empresas las que se están resistiendo, dicen: "bueno, sí, pero solamente algunos días a la semana, etc." Quieren tratar de reducir la presión sobre el teletrabajo porque sienten que pierden competencias; y eso tiene, para ellas, por un lado, repercusiones sobre la productividad y sobre la calidad del producto. Por otro lado, el tema que se plantean los trabajadores es al nivel, de la sociabilidad del teletrabajo. Se preguntan: “¿cómo se me va a evaluar?”. Este es un tema que a los trabajadores - consciente o inconscientemente - les preocupa, porque ¿se va a evaluar por el trabajo producido? ¿Cómo si fuera trabajo de destajo? ¿Se va a evaluar por la capacidad de resolver problemas? Todo trabajador sabe que, en última instancia, hoy en dia, sobre todo en los productos relativamente complejos, la producción es una combinación del trabajo de todos los trabajadores, de una combinación compleja de los trabajadores que trabajan en colectivos, en equipos, etc. Entonces, se sienten muy desamparados frente a la evaluación sustantiva de esta modalidad de trabajo, de la que no saben cómo va a funcionar. Esto es un segundo problema que me parece bien importante. La tercera cuestión que surge que es clara, y que uno lo ve desde acá en Uruguay, pero también se ve en Europa de distintas maneras, es: cuál es la realidad detrás de la relación teletrabajo, ya que hay múltiples tipos de teletrabajo. Es decir, hay una tendencia a decir: "bueno, todo es igual." No, no todo es igual. Hay trabajadores que realizan como teletrabajo, en realidad, como operadores, es decir son trabajadores que están, por ejemplo, alimentando bancos de datos, es decir, están entrando en computadoras la información que le dan, etc., o desempeñan algún otro tipo de tareas, de tipo rutinario. Este tipo de trabajo tiene fracturas importantes. Eventualmente, hasta se pueden llegar a trabajar todo el día, o todos los días en la medida en que le pasen información y el la procesa, etc. En este tipo de trabajo, en general, el problema que tiene es el de la supervisión, porque es un trabajo que requiere indefectiblemente supervisión. Pero, a esta altura, ya hay experiencias bastante negativas desde la percepción del trabajador, en el sentido de sentirse bajo una supervisión, casi detectivesca o policial. Hay supervisores 
que se pueden meter en tu computadora para ver si está trabajando en ese momento. Por otro lado, pueden también ver que qué hiciste durante el horario de la jornada de trabajo y por ahí te puede pasar que tú o tu mujer se le ocurrió "che, capaz que me gustaria irme a Portugal en las próximas vacaciones, o qué sé yo". Y se metió en páginas de las agencias de viajes; entonces al rato tienes el aviso: "Mire, señor que vemos que usted no está trabajando. Está mirando agencias de viajes". Este tipo de cuestión genera una terrible tensión en torno al teletrabajo. Esta es posiblemente la situación que tense más fuertemente el teletrabajo de los operadores.

Pero hay otro tipo de trabajador que está haciendo teletrabajo que son lo que se denominan, los actores del trabajo, son trabajadores cuya exigencia por parte de las empresas es que sean creativos, que estén resolviendo, o estén generando nuevos software, nuevas aplicaciones, nuevas ideas. Estos se sienten aislados porque este tipo de cuestión generalmente es una producción colectiva, funcionan en equipos. Tengo experiencia y he consultado - a través de Zoom y a través del teléfono - a muchos colegas que están en este tipo de trabajo, y lo que te dicen es lo siguiente: "Mira, el teletrabajo es posible si es por algunos días a la semana.”. Esa es la primera condición. Y la segunda condición que te ponen el estar en un equipo que estén bien consolidado. Me decía por ejemplo una encuestadora que se dedica a encuestas de opinión pública: "Nosotros podemos trabajar en teletrabajo hasta cierto punto, porque de alguna forma tenemos una enorme experiencia, entonces sabemos que el que tiene que hacer los cuestionarios, rápidamente los arma y sale. Y nosotros sabemos que si le decimos no sé si viste tal cosa o tal otra, inmediatamente reacciona. Por ello se puede recurrir al teletrabajo, pero esto puede durar cierto tiempo, porque la verdad es que capaz que involuntariamente podemos ir perdiendo este tipo de conocimiento del otro que nos da el estar en contacto, además del tipo de conocimiento que tenemos de nosotros mismos, de nuestras limitaciones relativas que cubre el compañero, etc.”. Al diluirse el trabajo de grupo se generan enormes dificultades. La tercera gran dificultad es el problema del tipo de comunicación que te lleva el teletrabajo. Es un poco de lo que me pasó con Eduardo recién. Yo terminé de hablar. Eduardo tuvo que pensar, prender la computadora, consultarme. No puede ni se le ocurre 
intervenir para decirme: "che, a ver, explica o ¿puedes desarrollar más esta idea?”. Lo que sí pasaría muy fácilmente en una reunión del tipo informal, digamos. Si estamos cara a cara, rápidamente, puedo entender y puedo responder, aclarar lo que quería decir. Con el teletrabajo, quieras o no, hay un protocolo, el que habla uno a la vez, etc. Piensen si fuésemos treinta personas que estamos comunicados. Uno me hace una pregunta y yo se la contesto, pero él no está totalmente satisfecho de la contestación que le di. Y tiene que esperar todo el ciclo para volver a preguntarme, capaz que ya dejamos el tema y estamos en otra cosa. Entonces, esta situación genera enormes dificultades y hace a todo lo que se llama competencias colectivas y que la literatura la llama, competencias no cognitivas; porque no son, no emergen directamente de los conocimientos adquiridos académicamente, sino que son un producto del, (lo digo en francés), savoir faire. Un saber hacer, que es necesario para realizar el trabajo; y esto es válido tanto entre trabajadores como entre los trabajadores y la jerarquía, y como también en la relación que se da entre los trabajadores y el público.

Ana Paula: ¿Podrías hablar un poco al respecto de la intensificación del trabajo emocional y la modulación que tenemos que hacer de las emociones para trabajar en el ambiente familiar, donde las esferas están juntas?

Marcos: Yo te pediría que distingas entre el trabajo emocional y las emociones en el trabajo. Creo que son dos cosas distintas. Sobre todo, sobre el trabajo emocional hay toda una literatura, acaba de salir, creo que un colega de ustedes, un brasileño acaba de sacar una reseña sobre el trabajo emocional que muy rico. En resumen, se entiende el trabajo emocional a la dimensión emocional del trabajo que intenta movilizar el manager para de una forma muy seductora, llevar al trabajador que trabaje más, etc. Existe toda una orientación muy productivista de la manipulación de las emociones para el trabajo. Esto es todo un tema y yo no me refería a eso porque estaba hablando del ámbito familiar en el mundo del trabajo. Con respecto a las emociones en sí, nosotros las tenemos en relación al contexto del teletrabajo, en este caso concreto, relaciones con nuestros hijos, nuestros nietos en mi caso. 
Eso es un tema que tiene su problemática específica. Y yo creo que también el tema de las emociones pasa esto en el área del trabajo en sí aunque quizás de otra manera. Una de las primeras mujeres que hizo el trabajo etnográfico en fábricas fue durante la guerra la segunda guerra mundial. Simone Weil - una filósofa y socióloga francesa, entró como obrera en una fábrica -, y comentaba que había veces que una mala actitud de su capataz hacia ella, diciéndole un dispararte o alguna grosería, la dejaba molesta todo el día. Este tipo de situación de violencia que no es física, ya que es simbólica, repercute sobre nuestra productividad, sobre el trabajo, sobre nuestra realización en tanto que trabajadores. Creo que hay todo un campo - esto que yo llamo las competencias no cognitivas - que me parece muy importante, en donde la dimensión afectiva, no solamente emocional sino afectiva en sí ya que es relacional, es muy importante. Me iba a referir a ello más adelante, pero quizás lo pueda decir ahora. Creo que una de las cuestiones que más genera un mayor cuestionamiento, y que poco se trabajaba por parte de los académicos al respecto, es el tema del valor/trabajo. No sé qué pasó en Brasil concretamente, pero se lo pasó en Europa y lo que pasó en Uruguay. Esta cuestión que se armó casi espontáneamente que a las 8:00 de la noche, de aplaudir a la gente que trabaja en la Salud, no solamente a los médicos, también a los enfermeros, y a todo el personal que estaba trabajando con gran riesgo durante la pandemia. De alguna en el acto de los aplausos hay un reconocimiento del valor de lo que estaban haciendo, arriesgando sus vidas, etc. Sin embargo, este valor no tuvo ninguna repercusión de punto de vista monetario. Es decir, en este contexto se da una escisión entre lo que es el valor en términos capitalistas, en sentido qué es lo que yo aporto a la generación de riqueza para el sistema, y más concretamente a las empresas - y por eso se me paga una cierta cantidad - de lo que es el valor que tiene mi trabajo en relación a la sociedad. Y yo creo que esta situación muy particular, quizá no sea por mucho tiempo, de alguna forma hace que repensemos el tema del valor del trabajo, que no solamente podriamos y tendriamos que reconocer el trabajo en función de lo que aporta para el capitalismo, sino que tendriamos que hacer un reconocimiento de lo que es el valor del trabajo en función de lo que aporta para la sociedad, y para materializar este valor, tendría que tener 
algún tipo de remuneración especial. Hablo de esto porque esta escisión fue lo más visible, en relación a los trabajos de salud, pero ¿qué pasa con los trabajadores de la limpieza?, ¿y los de la basura? del montón de servicios que de alguna forma no se pudieron detenerse, porque si no, lo que se hubiese generado caos absoluto en la sociedad. ¡Es evidente! En Francia hoy en dia hay una encuesta muy importante que se ha hecho, dirigida por una socióloga, del principal instituto de estadística francés, muestra que el riesgo de la gente que trabaja en la basura es muy importante, porque esta gente que ya tiene un riesgo de infección anterior. El 20\% vive de esta población vive en situación de mucha concentración de personas, o sea hay situaciones de hacinamiento. Entonces estos trabajadores están sometidos a un doble riesgo de contagio: el propio del trabajo porque no se interrumpe y el del hacinamiento. Están expuestos a dos vectores posibles de infección. Entonces todo esto nos lleva, al menos creo que se abre la posibilidad, de pensar todo tema de cómo se valoriza el trabajo, cómo pensarlo desde otras perspectivas que el de la centralidad del capitalismo en la organización de nuestras sociedades. ¿Me sigues en el razonamiento?

Entonces yo lo que propongo y siguiendo un poco la línea de la teoría crítica de Axel Honneth y de otros, es el de tomar el criterio del reconocimiento como criterio fuerte para recomponer una escala que se concretice simbólicamente a través de la remuneración. Un reconocimiento que este tipo de trabajo es indispensable en nuestra sociedad. Y, por lo tanto, tendría que ser remunerado, no en función del nivel educativo alcanzado ni de otros mecanismos de selección y jerarquización que establece el sistema capitalista, sino directamente por su relevancia para la sociedad. Lo que queda clarísimo en este contexto.

Ana Paula: Y sobre la parte de la intensificación del trabajo, donde trabajamos mucho más que antes en el contexto del teletrabajo, ¿no te parece?

Marcos: En términos generales comparte esta apreciación. Creo que hay situaciones relativamente excepcionales. En Uruguay ya antes del Covid-19, se utilizó una plataforma en la actividad docente. Ella se llama la plataforma 
EVA, que es un sistema por el cual los docentes colocamos toda nuestra biografia de nuestros cursos, o sea que los estudiantes directamente en la plataforma y bajaban el texto que le habiamos mandado leer para debatir. Un 96\% de los docentes de la Universidad utilizaban este sistema. E1 sistema tardó cierto tiempo en instalarse, pero de alguna forma nos facilitó mucho el pasaje del trabajo directo al teletrabajo, porque ya tenía, ya había una especie de relacionamiento en torno al teletrabajo a partir de las plataformas y la actividad docente de teletrabajo apareció como una extensión de una práctica que ya habiamos incorporado a la docencia. Aun así, a partir de la evaluación que realizó la propia Universidad, se requerian cursos para los docentes para realizar teletrabajo docente y estos efectivamente se dieron - cosa que en muy pocos lugares que yo sepa se han dado - tratando darte ideas, de cómo mejorar la pedagogía en estas condiciones de enseñanza, de cómo mejorar la comunicación por teletrabajo, etc. Aun así, sé que ya está programado para febrero, marzo, nuevos cursos para docentes. Ya no para gente que tenia una enorme experiencia docente, sino para gente que tenía poca experiencia porque se inicia en la carrera docente. Para ello hay un equipo universitario, que alguna forma tuvo que entrar a sistematizar la experiencia, y a generar opciones pedagógicas orientadas a ver cuál es la mejor forma de enseñar a través del teletrabajo. Esto es la Universidad, es cierto la universidad uruguaya, con muchísimos estudiantes, que son aproximadamente 80.000 estudiantes, etc, pero es la Universidad. ¿Se imaginan lo que es llevar a la docencia por teletrabajo en primaria y en secundaria? Debe ser desesperante para un docente de secundaria o para un maestro el comunicar y mantener el interés de sus alumnos con esta modalidad de docencia. Y ello, más allá, que se corrió en suerte, con el tema de las computadoras gratis para los niños. Tú sabes que todo estudiante de primaria recibe una computadora gratis al entrar en el sistema. Este plan se llama el Plan Ceibal y las ceibalitas se llaman a estas computadoras que se reparten, y que les permite de alguna forma da a los chicos tener experiencia de un cierto uso de las computadoras, incluso en las escuelas rurales. Pero aún así, el trabajo del docente fue enormemente difícil, entre otras cosas porque con el Covid-19, en Uruguay, como en Brasil supongo, el momento en que empezó la consciencia de la pandemia, y se 
comenzaron a tomar medidas de suspensión de las clases, fue cuando empezaban los cursos en las escuelas y los liceos. Entonces, pueden ustedes imaginense a niños que ni siquiera conocían a sus maestro/as, que no han establecido una relación afectiva con él o la mismo/a y que de repente se tienen que comunicar con ella por computadora, con el señor o la señora que está del otro lado de la computadora, que intentan mostrar todas las simpatías que pueden, pero, en fin, que ellos mismo saben que suena bastante poco realista, poco auténtico, trasmitir la simpatía en el régimen de teletrabajo. Entonces de alguna forma esto generó líos muy importantes en primaria, como supervisores que no tenían experiencia, con falta de comunicación - como decía Eduardo - falta de comunicación entre los propios docentes, con chicos que se cansaban muy rápido, porque es difícil mantenerse en atención así, con padres que estaban detrás de los chicos y que no tienen experiencia en este tipo de actividad docente y por ahí se volvían represivos con los chicos, etc. Ahora bien, lo que es increíble y yo creo que por desgracia creo que en Uruguay no se aprendió suficiente ya que no se llevó a sistematizar correctamente la experiencia es que todo esto funcionó muy aceptablemente porque había una "muy buena onda", es decir la preocupación era tal por el tema del Covid, que todo el mundo aceptó pasablemente las malas condiciones de trabajo. Las asumió como un dato de la realidad, se digo: "Bueno, hay que poner buena cara a esta situación". Yo me pregunto, si el año que viene que seguramente va a dar un repique del Covid, ¿si la situación va a ser la misma? Es por ello que considero que no se aprovechó bien esta experiencia para sistematizar y para tener orientaciones más finas, sobre todo, para la enseñanza masiva en el año entrante.

Eduardo: Siguiendo con el tema del teletrabajo, ¿cuales serian para ti las posibles demandas de conflictos en esta situación?

Marcos: Sí, yo creo que los conflictos, algunas cosas ya mencioné al pasar. El tema de la preservación del colectivo de trabajo es una fuente muy importante de conflictos. La exigencia de reunión informal, las pausas para el café, la información no formalizada, etc., es un tema muy importante y 
que genera tensiones relativamente importantes. Una segunda fuente de tensiones son las cadenas de trabajo, la necesidad de tener cadenas de trabajo claras y previsibles. Si llegamos, de alguna forma, a la ley que se votó en Argentina, o que se está tratando, que ya tiene media sanción - o sea ya pasó con los senadores y ahora está en diputados en Uruguay -, de fijar playas horarias, es decir horarios fijos que uno puede hacer teletrabajo o no, esto puede ser una fuente de tensión relativamente importante. Yo personalmente sostengo que como se están procesando las leyes en América latina, me parece que es de una forma excesivamente general, y es muy difícil establecer claramente cuáles son las situación y relaciones de trabajo que se dan con la modalidad de teletrabajo. Creo que por lo menos hay que distinguir dos situaciones. Una es hacer teletrabajo en comunicación directa con la empresa, con el centro de cómputo, de informática de la empresa, otra cosa es hacer teletrabajo solo sin una relación directa con su empleador. Yo creo que son dos cosas distintas porque, por ejemplo, ustedes son docentes, y alguna vez pasarán el sábado de mañana poniéndose a corregir exámenes o a preparar una clase. Eso está en el límite del teletrabajo y puede ser teletrabajo también, pero el tema central es que esta actividad es imposible controlar, ¿cómo podría controlarse? ¿Con un inspector que te toca el timbre y te pregunte "estás trabajando"? Es absurdo. Lo que sí me parece muy importante es el control con respecto a la relación, o el tiempo disponible, o el tiempo presencial que a uno le requiere su empresa. Este es el tema que de alguna forma es necesario acordar con un Convenio y hay sindicatos que exigieron esto. Esto no está registrado en todos los proyectos de ley que se están discutiendo. En alguna ocasión, los sindicatos exigieron que, para que se cumpla el dispositivo de "cortar" la comunicación del trabajador con la empresa, esta debería ser realizada por la propia empresa y que no quedase a voluntad del propio trabajador. Primero, porque al hacerlo la empresa, de alguna forma se corta con todos los trabajadores, funciona como el silbato de una fábrica que señala el fin de la jornada. Pero, segundo, porque al hacerlo así, la empresa es controlable por la inspección del trabajo. Entonces, la carga de estar conectado o no estar conectado no pasa por la voluntad o la responsabilidad del trabajador, sino que pasa por la propia empresa. Yo estoy muy a favor de las leyes que se están votado, lo digo 
sinceramente. Prefiero tener leyes que no tenerlas. Todas las leyes necesariamente van a cambiar y se van a perfeccionar y mejorar, pero no tener ningún tipo de regulación esto es darle pie al capitalismo más salvaje. Pero tampoco hay que ser ingenuo, en gran parte, en términos generales las leyes laborales existentes y los convenios de la OIT están en condiciones de regular en términos generales, el teletrabajo. Por lo que es necesario ser cuidadoso de ver si las nuevas leyes de teletrabajo de hecho le están haciéndole perder derechos a los trabajadores.

Otro tema vinculado a este, o indirectamente vinculado a este, es lo que una socióloga francesa que se llama Marie-Anne Dujarier que escribió, un libro que se llama "El Management Descarnado" Y en él señala que crecientemente empieza a haber un management que se hace por modelos de management, es decir "hay que hacer esto, hay que hacerlo así, si vos te desvias de eso te sanciono, o de alguna forma te castigo". Ello, sin tomar en cuenta todos los imponderables a los que está sometido el trabajo real, todas las situaciones de contexto en las cuales se desarrolla el trabajo. Entonces este management, que se hace por teletrabajo, de alguna forma es enormemente represivo, y eso está generando obviamente una situación malsana en la cual los trabajadores como reacción su vez, tratan de apropiarse del espacio y de su libertad, cambiando las reglas de los juegos, realizando trampas, o haciendo "otras cosas" en el tiempo de trabajo, pero sin que se sepa. No creo que esto sea sano. Esto como les decía, esto de los "espías" sobre tu computadora - hoy en día se venden por internet estos espías - se puedo comprar un espía y con él me comuniqué con Eduardo meterme en la computadora de Eduardo, y a partir de ahí saber y tener exactamente todo lo que hizo con su computadora, y cuando estuvo trabajando, y cuando no estuvo trabajando. Y si esto ya esto ya existe, no es una cosa del mundo futuro, podemos imaginar el futuro que viviremos. Eso genera tensiones de trabajo terribles y lo que está mostrando - y es una de las cosas que está preocupando mucho el management norteamericano y europeo porque ya está pasando - es el desaliento creciente de los trabajadores y la caída de la productividad del teletrabajo. Muchos de los empresarios que se resistan a adoptar el teletrabajo por problemas de organización interna o por la razón que fuera, también señalan que el 
teletrabajo está generando una bajada de la productividad de sus empresas. Yo estuve rastreando y en Suiza, por ejemplo, ya hay recomendaciones de especialistas, psicólogos, que están planteando que es negativo más de dos días de teletrabajo por semana. Esta situación, digamos, de desaliento, es una forma de reacción conflictiva frente a una situación en que la gente no se siente cómoda. No se expresa tanto, como por ejemplo de los trabajadores las plataformas en grandes huelgas como se ha dado en São Paulo, pero se expresan de otras maneras. Capaz que son más dificiles de alguna forma de transformarse en una relación de fuerza porque no tienen una visibilidad, pero está ahí, juntando bronca, y puede llegar a estallar en cualquier momento. Si alguien entra en conflicto abierto, este podría desembocar en algún tipo de diálogo y de él, encontrar un acuerdo. Pero es muy dificil llegar a acuerdos con gente que está desalentada y llega hasta odiar su trabajo. Otra cuestión que aparece muy fuertemente es la preocupación por parte de muchos sindicatos de la pérdida de contacto con sus trabajadores. Yo creo que esto es solamente válido si el teletrabajo es full time, o sea 40 horas por semana y quizás más. Este contexto de trabajo le haría perder mucho peso a los sindicatos, por dos razones: primero, porque es dificil construir con teletrabajadores full time, acciones colectivas. Pero a su vez, porque los propios teletrabajadores de alguna forma van perdiendo su relación con el colectivo general de los trabajadores, es decir la idea de clase, etc. Por ello, los sindicatos están muy, pero muy preocupados por esta situación. Yo creo que cómo está sucediendo últimamente en muchos lugares, son las situaciones limite las que generan las acciones colectivas. Por ejemplo, hay una situación que pasó hace quince días en Marsella: un trabajador se suicidó. No era de teletrabajo, pero se suicidó por el hostigamiento, el ataque continuo por parte del management de su trabajo. El sindicato estaba muerto desde hace 15 años y de repente, resurgió con una fuerza bárbara. Entonces, creo que no hay que perder de vista, que no hay que crear mecánicamente una especie de "ah! pasó tal cosa" o tener una reacción de tal tipo. Sino que hay situaciones de acumulación, de desaliento que de repente, "clack", hay un evento que las hace saltar y todo el mundo queda sorprendido. 
Para hablar más en general, nuevamente me estoy yendo un poquito del tema del teletrabajo, pero uno percibe lo que pasó en Chile en los últimos años y bueno, los sindicatos están enormemente ..., con tasas de sindicalización bajísimas y muy divididos, etc. Sin embargo, ahora el día que saltó, se quemó la pradera digamos. No había mecanismos, este gobierno se encontró sorprendido, recurrió a lo único que se le ocurrió, porque tiene el palo cruzado en la cabeza, de la represión y así le fue, cambio de constitución, etc. Todos tenían la impresión de que hay una reorientación en Chile, cuando pasaron con el "maravilloso" modelo neoliberal que se basaba en una represión muy fina, y por ello, con obviamente una conflictividad casi inexistente. Y Ustedes ven, que esta conflictividad surge de una forma totalmente distinta a la que el gobierno tenía prevista. Entonces, el tema de los trabajadores y de los sindicatos es un tema que está preocupando mucho a los sindicalistas actualmente en Chile, creo. Hace poco, hablaba con sindicalistas colombianos que estaban preocupados por el teletrabajo, y yo les comentaba que habian algunas experiencias, no demasiadas, pero interesantes en el sindicalismo francés sobre este tema. El hecho que existan sindicatos de funcionamiento virtual, es decir sindicatos que funcionan a través de las redes - cuya función es darle información a los trabajadores, información que puede ser estratégica para estos últimos, y ello a partir de las propias de las propias redes y no solamente desde la tradición oral de nuestro sindicalismo, que siempre es una relación cara a cara, había logrado mantener poner en juego cuestiones muy relevantes para los trabajadores. Por ejemplo: es muy dificil en cierto tipo de teletrabajo saber cuánto se está pagando a los trabajadores y bueno, ellos empezaron a exponer públicamente - en línea - los contratos que proponía la empresa y entonces la gente comenzó a comentar: “¿cómo? A fulanito le está pagando esto por lo que hace ¿y por qué no me lo pagan a mí que hago lo mismo o más que él?”. Así comenzó a construirse una perspectiva colectiva. Yo creo que este tipo de experiencias son muy ricas, pero siempre son complementarias al trabajo interno de construcción colectiva de los sindicatos. Esto no va a sustituir al sindicalismo de tipo clásico, pero puede complementarlo.

Una última de las cuestiones que me parece importante señalar es que ya en algunos sindicatos empieza a haber cierto miedo al crecimiento del 
trabajo subcontratado o incluso del trabajo informal, a través del teletrabajo. ¿Cómo se sabe que una empresa no está, vía otra empresa sub contratada, contratando teletrabajadores para hacer tareas por menor salario? ¿Cómo se sabe? ¿Cómo se tienen garantías que ello no ocurre? ¿Está prohibido o no está prohibido algo así? De hecho, legalmente no está prohibido. Entonces el tema de la flexibilidad y el tema de la tele-regulación del trabajo puede ser un campo en todavía los sindicatos no estén demasiado comprometidos y le voy a decir porqué. Estuve pensando mucho sobre este tema y una de las cuestiones que yo estaba mirando es que es lo que sucede en Francia (discúlpame la continua referencia a Francia, de hecho, he buscado estadísticas por todos lados, pero he encontrado más fácilmente estadística de Francia). Y en este país el 49,9\%, de los teletrabajadores en Francia, son cuadros superiores, y los trabajadores obreros calificados y obreros no calificados, representan solamente el $1 \%$, de todos los teletrabajadores. Entonces uno podría pensar, creo que con cierta ingenuidad: "Bueno, pero esto no es un tema nuestro. No es un tema de los trabajadores ni de los sindicatos". Creo que esto no es así. Volveré luego sobre este tema, pero en sí, durante años y años, el modelo que estaba de hecho, por detrás en todas las relaciones laborales era el modelo del que se daba en la producción del automóvil; de allí las referencias al fordismo y luego al toyotismo, por ejemplo. Hoy en día, claramente, este modelo de relaciones laborales ha variado hacia los modelos de trabajo en la informática, y es a partir de la idealización de las relaciones que se dan en esta actividad económica, que se van a ir construyendo modelos para toda actividad económica. Y poco a poco su lógica subyacente se legitimará a través de normas jurídicas. Me parece que este es un tema extremadamente complejo y que no podemos, en la academia no abordar; y los sindicatos, no pueden dejar de mirar para este tipo de cuestión porque quizás en ello dependa su vida. Pero, por otro lado, el otro tema que se da es el siguiente: el 60\% de la fuerza de trabajo en América Latina trabaja en pymes, en las pequeñas y medianas industrias. En Uruguay esta cantidad asciende al $70 \%$. Sabemos que el teletrabajo tendrá más dificultades a insertarse en la Pymes. Sin embargo, hay que dividirlas en dos, las Pymes que son altamente electrónicas, que son pequeñas empresas de con cinco, o seis trabajadores, pero altamente 
calificados, y otras que no, que hacen tareas casi artesanales, servicios, con mucho trabajo manual. Yo creo que solamente las pymes de este segundo tipo tienen más dificultades de orientarse con el teletrabajo que las empresas grandes, comerciales, industriales o de servicios o que el empleo público. Pero aun así, el tema del teletrabajo poco a poco las va a alcanzar, y este es el tema que me preocupa y que me parece que los sindicatos tendrían que ser más vigilantes sobre este tema. Entre otras cosas, por ejemplo, en la ley uruguaya, o el proyecto de ley ya que todavía no está sancionado, se sostiene que no se puede cargar más con impuestos a las pymes, porque son de bajo capital y los costos del teletrabajo pueden ser altos en términos relativos. Es terrible, porque lo que se propone es que los costos materiales del teletrabajo pasarian a ser costos para el trabajador, las computadoras, el precio de la conexión, deberán pagarlo los propios trabajadores. Más allá de todo, del disturbio espacial en los hogares para los teletrabajadores se le agrega un costo que va a representar, evidentemente una reducción de su salario, en realidad reducen su salario real. Entonces esta idea de promover el teletrabajo en las pymes bajando el salario del trabajador me parece lamentable. Yo por lo menos lo encaré así y así lo he escrito en algunos artículos al respecto. Pero insisto, igual que me parece muy importante que se regule el teletrabajo legalmente, porque de alguna forma le da visibilidad y uno puede encontrar armas legales para pelear contra cierto tipo de regulaciones que establece la propia ley, que, si no se hacen legalmente, igual se harán en la práctica.

Ana Paula: Acá en Brasil tenemos Ifood, Uber Eats, entre otras actividades que se hacen por plataformas ¿Cómo ocurre esto en Uruguay?

Marcos: En Uruguay hay plataformas importantes. Obviamente en algunos tipos de actividades que se realizan por plataformas, lo que en realidad es muy importante es lo idiomático. Uruguay trabaja mucho para España en plataformas de call centers. Todo lo que es el procesamiento de las quejas muchas de empresas españolas, se procesan en Uruguay. Acá en Uruguay se dio una situación muy particular en la cual los trabajadores de las plataformas pudieron construir un sindicato. Sindicato que puso una serie 
de marcas muy importantes en materia de condiciones de trabajo, que de alguna forma construyeron un espacio realmente interesante. Aun así, el promedio de tiempo de trabajo en un call center, son más o menos cuatro meses, luego se va a otra actividad laboral. Uno puede decir con esta fluidez de la fuerza de trabajo, ¿cómo es posible que tenemos sindicatos? Y lo tienen, y ello me parece muy importante. Con las otras plataformas, las del transporte de comida rápida con bicicleta, motitos por ejemplo, hay un trabajo que sé que el Plenario Intersindical de Trabajadores-Convención Nacional de Trabajadores) PIT CNT, está realizando, particularmente el sindicato su sindicato que aglutina a los trabajadores del comercio, está trabajando mucho en la construcción de un sindicato que agrupe a estos trabajadores del delivery, pero todavía no hay un sindicato fuerte. $\mathrm{Y}$ el tema central en este campo - y es como se dio en Europa -, es de si los trabajadores de esta actividad son independientes, o son asalariados. $\mathrm{Y}$ este es el punto clave. En Uruguay, hubo por ahora, solamente un reclamo de un trabajador de Uber que se le había realizado un contrato como empresario unipersonal y reclamó a la justicia que en realidad era un trabajador asalariado y ganó el juicio. Es decir que le tuvieron que pagar el despido en tanto que asalariado por el tiempo que trabajó para la empresa, porque de hecho lo habian despedido, mientras que si la justicia lo consideraba un trabajador independiente que era como había realizado el contrato, UBER no le hubiese tenido que pagar nada. Este antecedente todavía no generó consecuencias, pero seguramente va a ser más general de acá a un tiempo. Otro tema que está pasando, pero esto es a nivel mundial, y que me parece bien interesante, es que por primera vez en Europa empieza a haber una alianza entre los trabajadores del taxímetro y los trabajadores de Uber, y ello contra Uber. En América Latina, este tipo de situación todavía no se planteó todavía.

Sobre el teletrabajo, en el contexto de Latinoamérica, y en el contexto central del capitalismo, nuevamente acá hay que ponerla en el contexto del Covid. Es imposible no ver todo este tema del teletrabajo. La eclosión del tema en Uruguay saltó de $3 \%$ de gente que hacía teletrabajo, en pocos meses, a $62 \%$. El caso es muy importante. En Francia se estima que van a ser un $34 \%$ de la fuerza de trabajo la que va a pasar al teletrabajo. Es decir, 
7 millones de personas haciendo teletrabajo. Esto ya genera problemas de saturación en las redes. Hay una serie de temas en lo espacial que son muy relevantes, pero a las que no me voy a referir. Yo lo que digo es que, lo que se estima, es que - y eso fue una parte fuerte del contexto - que el Covid va a generar un empobrecimiento global de la sociedad. Se estima que 150 millones de personas van a estar por debajo de los 2 dólares diarios de ingresos. La pandemia ha destruido 345 millones de puestos de trabajo en el mundo según un reciente informe de la OIT. Entonces creo con estos datos, estamos en un contexto que, obviamente, no permite muchas ideas de cómo salir, de cómo manejarse.

Lo que a mí me parece con respecto a esto, y quisiera insistir sobre esto, es que el modelo general de las relaciones laborales que siempre se pensó en términos primero de la industria, aunque luego se amplió los servicios, era básicamente el modelo de las relaciones laborales del automóvil como ya he señalado. Se pensaban entonces en las relaciones laborales en los servicios a imagen y semejanza de la industria. Esto se refleja en el New Deal norteamericano que se copia en Uruguay, y de allí surgen los convenios colectivos a partir de 1945, aunque la industria uruguaya nunca se produjo automóvil. Se armaron automóviles, pero nunca se produjo automóvil. De allí venían de esta visión de grandes convenios colectivos, con grandes categorías, con la estabilización de jerarquías por categorías, etc. Esto está cambiando, en la medida en que el capital industrial está perdiendo hegemonía con respecto al capital digamos financiero e informático. Hoy en día se habla de las GAFA ¿'Saben lo que es GAFA? Son las cuatro grandes empresas que están marcando el modelo de producción del mundo: Google, Amazon, Facebook y Apple - los GAFA, así se reconoce. Es cierto que, en Estados Unidos, en este momento, hay una lucha jurídica con Google por el tema del monopolio, y en Europa hay una pelea fundamental porque estas empresas no quieren pagar impuestos. Tienen tanto dinero que se pueden dar el lujo de decir: "no queremos pagar impuestos, y no los vamos a pagar". Todas estas situaciones que se están dando, si revisamos la historia parecen copiar al feudalismo. En su época de gloria, los grandes señores feudales, hablaban a los reyes y les decían: "miren muchachos, ustedes son reyes, pero los que mandamos somos 
nosotros!". Bueno, estas situaciones, son similares a las que se dan con las GAFA. Pero, de alguna forma, en esta emergencia, estas empresas están impactando terriblemente. Entre otras cosas - fijense que la situación dramática en que vivimos - uno puede estar en contra de las GAFA y, sin embargo ¿qué estamos haciendo? Necesitamos comunicarnos por Zoom. O Zoom está llegando, en este momento, creo, a casi 300 millones de personas que se conectan por Zoom. Es un salto brutal en estos últimos meses. Entonces podemos simplemente salir de Google, podemos decir: "Bueno, yo no quiero más estar vinculado a Google, no tampoco a Facebook, no quiero más los servicios de Amazon, etc.”. Uno puede restringirse y decir voy a tratar de comprar por otras vías los libros que no por Amazon, pero no, el tema no está ahí. El tema está en el impacto global que está teniendo y que es muy dificil combatirlos frontalmente, esto hoy en día parece muy difícil. Entonces esta situación en la que estamos atrapados genera una situación de cambio de todo, de concepción del trabajo, de la concepción de todo; inclusive de cosas que no tienen nada que ver con la informática, se van a empezar a regular a imagen y semejanza de las relaciones laborales y de consumo del sistema informático. Entonces esto me parece que es un tema que esta poco trabajado, poco estudiado y pensado. Yo creo que seguimos pensando en la clase obrera del siglo XX. Cuando hablamos de la clase obrera, no hablamos de la clase obrera de la época de Marx, hablamos de la clase obrera de la época de Lenin, o sea ya de grandes concentraciones de trabajadores. Hoy en día no es el caso, estamos en otro ámbito del mundo del trabajo, en otro ámbito del trabajo subordinado y con otras reglas que todavía no tenemos claro para dónde va, ¿qué reglas van a imponer?, ¿qué resistencias colectivas podemos reconstruir? Este es uno de los grandes temas que me preocupa. Con respecto a la primera parte, en el contexto de América Latina, lo que más me preocupa es el tema de qué tipo de teletrabajo. Yendo al teletrabajo en concreto, ¿qué tipo de teletrabajo se va a instalar en América Latina? Si es un teletrabajo tipo maquila a la mexicana, para el servicio de alimentación de bancos de datos yo creo que sería terrible, porque rebajaría mucho la calidad del trabajo y con él la identidad de los trabajadores en América Latina. Tengo miedo que esto se puede llegar a inundar digamos, de gente que hace este tipo de teletrabajo. La otra punta 
y eso creo que existe es, por ejemplo, Uruguay, que es el segundo exportador del mundo de software a medida ¿Pero cuánta gente ocupa? 15 mil personas. Es muchísimo, para un país del tamaño del Uruguay, pero realmente muy pequeño, pero aun así ocupa muy poca gente, y, además, es sinceramente una aristocracia laboral, son tipos que los salarios que ganan, es algo que uno no puede imaginarse. Y entonces esta es una nueva situación que está generada y que va a cambiar. Una de las cosas concretas que va a cambiar muy fuertemente a mediano plazo es la estratificación de la sociedad, cuáles son los criterios de estratificación en la sociedad. Y yo creo les adelantó - que toda esta vuelta digamos muy conservadora desde el plano político que tenemos en América Latina - después de un tiempo de gobiernos progresistas, es el de ir hacia atrás, en todos esos procesos de modernización. En realidad, es una combinación de líneas absolutamente orientadas por la lógica del capitalismo informático y financiero aliadas con los sectores más retrógrados de nuestras sociedades, que sienten que están perdiendo poder, y que buscan recuperarlo de cualquier forma, aunque seguramente van al suicidio, nunca volverán a poder tener el poder que tenian de forma legitima. Para esos sectores prolongar su situación de grupo dominante, no es peleándole el poder al capitalismo informático y financiero, sino tratando de bloquear todo espacio democrático a los sectores populares. Creo que estas dos tendencias unidas son producto de esta transformación que está teniendo el mundo y que nos repercute a todos. La tercera cuestión, y vuelvo a la idea del valor del trabajo. Yo estoy mirando, por ejemplo, que Facebook se ha planteado ir hacia un porcentaje muy importante del teletrabajo en los años que vienen, piensan que en 5 o 10 años van a ir al teletrabajo unos $50 \%$ de sus trabajadores. El teletrabajo, obviamente van a empezar por los gerentes. Esto es lo que están tratando de hacer. No es por abajo que se inicia este proceso sino por los cuadros del medio de la empresa, y esto va a generar, con el teletrabajo, una desconcentración de la población de estos gerentes en del Silikon Valle de California, que es en donde está instalado, y ello hacia sectores urbanos en donde la renta del suelo sea más barata. Zuckerberg, el presidente de Facebook dice: "Y no lo hacemos por razones humanitarias, para que la gente viva mejor, lo hacemos porque es más barato. Es más, pensamos ajustar los salarios al 
nivel de vida de cada lugar, donde la gente va estar y trabajar." O sea, volvemos a la vieja discusión de la época de Marx y Engels discutiendo lo que genera el valor del trabajo ¿Es el trabajo? ¿Es el costo del trabajo? ¿Es el mercado? Claramente acá, Zuckerberg es en este sentido más marxista que muchos de los que están diciendo que el salario se fija por el precio de mercado ¡No! Su verdad es que la tiene clarita; el valor está ligado al costo de la reproducción del trabajador, y "si le baja el costo de la reproducción del trabajador, yo también bajo el salario. ¡Total! ¡la ganancia por el aumento de plusvalía que puedo obtener, va a ser para mí, esto está clarísimo!" Algo similar sucede en Francia. La Confederación Nacional Patronal Francesa (CNPF), que es la asociación que agrupa a todas las empresas francesas, sostenía que había que pensar en bajar los salarios de los trabajadores, lo fundamentaba en que al hacer el teletrabajo, iban a tener mucho menos gastos de transporte “¿Los trabajadores entonces, porque se van a llevar más plata? ¡No, no!” Todo esto nuevamente hace, me parece, que en los años venideros el tema del valor del trabajo va a estar nuevamente en debate, y como sostenía previamente, es necesario e incorporar una visión que asuma la pregunta de que le aporta el trabajo a la sociedad, y no solamente al capital. Pero incluso, el debate, al interior del capital, es un tema que volverá a tener que ser repensados en un futuro cercano. Esta coyuntura, se ha transformado en un "analizador histórico" porque ha dejado visibles cuestiones que no las debatíamos más porque las tenemos muy interiorizadas como "naturales" sin siquiera nos damos cuenta que eran sujeto de controversia. Esta crisis ha permitido percibir ciertos fenómenos que te hacen repensar cómo está organizada la sociedad y como se redistribuye la renta. La última cuestión que yo digo en un largo artículo que escribí sobre el teletrabajo, que creo que va a salir publicado en la revista Relet que es la revista de Asociación Latinoamericana de Sociología (Alast), que a mí gran preocupación, es como el trabajador se siente aislado en este contexto. El aislamiento, insisto, tiene tanto repercusiones sobre la persona, como sobre la acción colectiva. Y en este último plano lo tiene repercusiones tanto sobre el trabajo colectivo, como sobre la actividad sindical. Y no es casualidad que la tendencia al aislamiento del trabajador, que es bastante anterior al teletrabajo, es una de las grandes preocupaciones que, en Francia 
se ha instalado que es el problema del suicidio laboral. Por suerte este tema todavía no se ha instalado en América latina. En Francia, el suicidio laboral es un tema en el cual, obviamente, se han metido psiquiatras, psicólogos, pero a esta altura también muchos sociólogos y psicosociologos porque de alguna forma se dan cuenta que no son solamente las pulsiones internas que tenemos te puede llevar al suicido, sino todo el contexto en el que se desarrolla tiene incidencia en el suicidio laboral, volvemos a Durkheim. Las tasas del suicidio no se explican por las psicologias individualmente consideradas de cada uno, sino por el contexto social en que se vive.

Ana Paula: Finalmente, para cerrar nuestra entrevista, queriamos preguntarte: ¿cómo estás viendo eso que el sistema educativo en su conjunto a partir de esta relación con el teletrabajo y con la situación puesta por el Covid-19?

Marcos: Una cosa fue el contexto de pandemia en el Uruguay en su primera fase, en donde se cerró toda actividad presencial y pasó a teletrabajo educativo desde la educación primaria, la secundaria y la terciaria, o sea la universitaria. Insistía en que la situación era muy dispar entre la universidad - que ya con la EVA, con el sistema de plataforma -, los estudiantes ya tenían cierto entrenamiento sobre el tema teletrabajo y se comunican por esa vía con docente y entre ellos por esta modalidad. Ya habían incorporado a su hábito de trabajo estudiantil el estar comunicados con plataformas. Eso facilitó, generó un contexto en el cual el teletrabajo pasó bastante bien. Tal es así que los resultados que estamos teniendo son que no afectó excesivamente, por ejemplo, la cantidad de títulos que se entregan por años, ni ningún otro indicador educativo relevante. Es obvio, que aún hay en el sistema educativo terciario sectores que el gran problema que tenian es lo que ellos mismos decian: "Bueno, nosotros pasamos a teletrabajo, pero no podemos seguir en este régimen toda la vida." Piensen ustedes lo que tiene que ver por ejemplo en medicina, con la actividad de laboratorio, con las atenciones a enfermos y otras actividades presenciales indispensables, hay toda un área de enseñanza que pasa por prácticas que no se pueden suspender un tiempo corto y volcarse a hacer enseñanza 
solamente por teletrabajo, de alguna forma esas carencias en las prácticas educativas no funcionan tan bien en el mediano plazo. También es muy especial Uruguay en ese sentido, la Facultad de Ciencias Sociales, la facultad a la que yo pertenezco, es una situación mixta porque soy profesor emérito, pero estoy jubilado. Bueno, mi facultad tuvo el primer caso universitario, de Covid-19, ¿y cuánto tiempo se encerró la facultad? Un día. Es muy distinto a las cosas que pueden estar pasando en Brasil, por eso la verdad es que nosotros casi me animaría a decir que tuvimos muy poco Covid-19 por ahora y es enorme la cantidad de decisiones drásticas que se han tomado para la cantidad de infectados que hay en la realidad; y la cantidad de muertos, llegan a cien en todo el territorio uruguayo. Estas cifras crecerán más adelante, es seguro. Pero también esto me parece que hay que asumirlo como contexto, porque también que me parece que es bien importante, y bastante distinto a lo que ha pasado en Brasil, por lo menos por lo que yo he visto. La segunda cuestión, y esto que se dio entre otras cosas, porque se han tomado medidas muy muy estrictas, y lo que es muy interesante que la pandemia se dio en un momento en el que un gobierno que se inicia, donde claramente todavía no hay temas nuevos sobre los cuales las fuerzas politicas se opongan. Tanto de los que estaban en el gobierno y que perdieron las elecciones - el Frente Amplio - y al nuevo gobierno, les cuesta salir de la temática de la campaña electoral. Más allá de eso, en esta temática de la pandemia, hubo un disciplinamiento enorme con las medidas propuestas por el gobierno, tanto a nivel político en general y también a nivel sindical. Los sindicatos se plegaron a las medidas que propuso el gobierno, pero incluso, sugirieron medidas a veces más duras, en el sentido de más represivas, de las que proponía el gobierno para disciplinar a la población con las medidas preventivas del coronavirus. Todo ello para contar que hubo una suspensión de presencia física de la enseñanza en todos los subsistemas educativos durante un periodo relativamente largo, cuatro meses por lo menos, no generó protestas organizadas por ello. $\mathrm{Y}$ es en este contexto de las cosas que yo puedo contar, las cosas que pasaron y se vieron dentro del sistema educativo. La primera es que claramente no se contaba con tecnologías adecuadas y había una falta de equipamiento suficiente en los hogares, para familias que los padres son ambos docentes, 
y el hijo que tuvo que tomar clases por teletrabajo, cuando en el hogar había una sola computadora. Todo este tipo de situación, con el grado de cansancio y de tensiones al interior de la familia que generó, las que más sufrieron fueron las mujeres. Por ello, es una cosa que a mí me llamó la atención, es lo poco que el feminismo ha intervenido en el tema del teletrabajo cuando evidentemente las más perjudicadas en esta circunstancia fueron las mujeres. Y esto sí se que ha "invisibilizado". Y me sorprende la falta de capacidad de reacción de los movimientos feministas al respeto. Bueno, la primera cuestión es la falta de tecnología adecuada y falta de equipamiento suficiente. La segunda cuestión es no haber recibido una formación sistemática previa, tanto del tipo pedagógico, por ejemplo, cómo se enseña a través del Zoom. Todos improvisamos, pero también falta de conocimiento tecnológico, cómo funcionan las computadoras, cuáles son las posibilidades que dan los programas informáticos, etc. La verdad es que nos mandaron a la guerra con un palito, porque no estábamos preparados para emprender estas tareas de ninguna manera. Todo esto que estoy contando lo puedo trasmitir porque empecé a llamar por teléfono a docentes para hacerme un panorama de lo que estaba pasando. Lo que cuento no es a partir de una muestra representativa de docentes, pero empecé a llamar maestros, profesores secundarios, profesores universitarios para preguntarle cómo les estaba yendo y qué dificultades tenían, etc. Insisto, no lo hice con el ánimo de generar estadísticas, pero lo que relato es simplemente un espectro de dificultades que me contaron que los docentes tuvieron. Una tercera dificultad importante era que no se contaban con lugares adecuados para realizar el teletrabajo. Muchas parejas jóvenes tenían poco espacio en su hogar, tenían sólo un cuarto, y por lo tanto trabajaban en el dormitorio o en la sala. Entonces los niños tenían que quedar en el cuarto para jugar o hacer otra cosa. A veces el compañero de la docente tenía que quedarse acostado en el cuarto porque la compañera necesitaba el espacio de la sala para teletrabajar. Todo este tipo de cuestiones fue bastante angustiante y generó tensiones importantes en el seno de la familia. Obviamente y esto vinculado a lo anterior, en la negociación de los tiempos y espacios con otros miembros de la familia, un espacio relativamente chico uno tiene que negociar: "Bueno, este espacio acá, discúlpame, todos en silencio porque yo 
voy a tener que teletrabajar". Esa negociación que se tiene que hacer - que de hecho nunca se hace con un protocolo escrito, artículo 1, artículo 3 -, se va construyendo en la práctica. Fue un proceso extremadamente complicado. Sobre todo, por lo que me contaban, con los niños que no entendían: "¿por qué si papá y mamá estando en casa, no podemos hablar con ellos?". Esa fue una cosa casi contra natura. La quinta cuestión era la falta de protocolos para supervisar el trabajo docente, tanto con la jerarquía, los supervisores, directores de las escuelas, los directores del liceo, con los coordinadores de las áreas educativas, docentes en la facultad, etc., como también la de poder compartir experiencias con los compañeros de trabajo. Hace poco le decía a Eduardo, bueno, se necesita hablar con otros docentes para que me digan cómo están encarando tal tema y cómo piensan dar tal otro, y como coordinar incluso hasta programas, "se va a ver Teoría 1, ¿hasta qué autor llegás?. Entonces este tipo de cosas no pudo procesarse correctamente, pero sobretodo lo que más pesó fue el problema con la jerarquía. ¿Por qué? Porque la jerarquía tampoco tenía ninguna experiencia de cómo manejarse en esta situación y tuvieron que improvisar, y algunos obviamente improvisaron mal, es decir, le salió la autoridad, la autoridad, autoritativa: "eso es así, eso es asá". Y ello generó muchas tensiones, mucha violencia reprimida. Otro problema también que se dio - ya que no había nada previsto al respecto - fue la transferencia de los costos, tanto de las computadoras - todo el mundo trabajó entre otras cosas con el equipamiento propio que tenía en la casa -, pero también los costos de conexión, los costos del tiempo de utilización de electricidad, etc. Esto generó otro problema importante. Hasta aquí, con todos este cúmulo de cuestiones se puede pensar: "Bueno, se calentaron [enojaron], armaron un escándalo.” ¡No! Lo que es extraordinario es que todo esto se hizo con una extrema "buena onda", es decir no hubo manifestaciones colectivas de bronca, capaz que individualmente sí puntualmente, que alguien se calentó con el director del colegio y le dijo "no sé qué", o qué alguien se calentó con el decano, o qué... pero siempre a título individual no hubo acciones colectivas ni espontáneas ni institucionalizadas a nivel político o sindical. Insisto, hubo una gran "buena onda". Ahora el problema es que yo creo que se viene una segunda ola de Covid y ahora sí en serio, con muchos contagios y lo que pasó fue 
toda una especie de preparación para cuando se venga. Pero ahora se viene, creo que después del verano, creo sinceramente que es una lástima que no se haya sistematizado la experiencia vivida. Porque la próxima ola de la pandemia si va a generar protestas por la falta de previsión de estos problemas antes señalados. Además, van a aparecer nuevos problemas de los cuales todavía no registré en las charlas con los docentes. ¿Cuáles eran los problemas que yo pienso que empiezan a aparecer un poquito más adelante y todavía en mis entrevistas telefónicas no aparecieron? Son los problemas de salud; los dolores de espalda, los dolores de cabeza, el burnout, la exigencia mental. Estos problemas creo que ya empezaron, pero se va a tener consciencia de ellos posteriormente. Y finalmente, el último problema que empezó a aparecer, y qué insisto que está ligado básicamente al carácter expresivo del trabajo docente, es decir no es un trabajo que se encare de una forma utilitaria, sino que el propio docente intenta realizarse en su propio trabajo, Le importa el resultado de lo que hace. En los sectores laborales de una sociedad, siempre hay dos que tienen una dimensión dominantemente expresiva, estas son la educación y la salud. Y en la educación esta orientación expresiva de los docentes generó una preocupación muy importante sobre el impacto del teletrabajo sobre la educación de los chicos. ¿Qué estamos generando cómo nueva generación de estudiantes? ¿Qué carencias va a tener esta generación con respecto, a las generaciones que no pasaron por el COVID? Surge una profunda convicción, que los que aprovecharon menos los cursos por teletrabajo durante la pandemia, fueron los de las clases menos pudientes. Este es un problema serio y que los docentes son absolutamente conscientes y que de alguna forma se preguntan: "Bueno, ¿y qué se está haciendo para resolver esto?" y aquí si hay demandas, inclusive a nivel sindical, a las autoridades educativas. ¿Cómo resolver esto? ¿Cómo encaramos políticas para apoyar a estos muchachos de bajos recursos? Y por aquí termino la charla.

\section{Sobre o entrevistado:}

Marcos Supervielle profesor emérito da Facultad de Ciencias Sociales (UDELAR/Uruguai). Profesor de sociología de la Universidad de la República, Montevideo, Uruguay. Coordinador del área de Sociología del Trabajo del Departamento de Sociología de la Facultad de Ciencias Sociales. Master de Sociología en Paris VIII (1978) e Licencia de Sociología en Paris VIII (1972). 